\title{
Proximity Does Not Equal Access: Racial Disparities in Access to High Quality Dialysis Facilities
}

\author{
Milda R. Saunders • Haena Lee • Chieko Maene • \\ Todd Schuble $\cdot$ Kathleen A. Cagney
}

Received: 7 April 2014 /Revised: 11 July 2014 / Accepted: 23 July 2014 / Published online: 15 August 2014

(C) W. Montague Cobb-NMA Health Institute 2014

\begin{abstract}
Background For patients receiving hemodialysis, distance to their dialysis facility may be particularly important due to the need for thrice-weekly dialysis. We sought to determine whether African-Americans and Whites differ in proximity and access to high-quality dialysis facilities.

Methods We analyzed urban, Whites, and African-Americans aged 18-65 receiving in-center hemodialysis linked to data on neighborhood and dialysis facility quality measures. In multivariable analyses, we examined the association between individual and neighborhood characteristics, and our outcomes: distance from home ZIP code to the nearest dialysis facility, their current facility, and the nearest high quality facility, as well as likelihood of receiving dialysis in a high quality facility.

Results African-Americans lived a half-mile closer to a dialysis facility $(B=-0.52)$ but traveled the same distance to their own dialysis facility compared to Whites. In initial analysis, African-Americans are $14 \%$ less
\end{abstract}

M. R. Saunders $(\bowtie) \cdot H$. Lee

Section of Hospital Medicine, Department of Medicine, University

of Chicago Medicine, 5841 S. Maryland, MC5000, Chicago,

IL 60637, USA

e-mail: msaunder@medicine.bsd.uchicago.edu

H. Lee

e-mail: hnlee@uchicago.edu

M. R. Saunders

MacLean Center for Clinical Medical Ethics, University of Chicago,

Chicago, IL, USA

H. Lee $\cdot$ K. A. Cagney

Department of Sociology, University of Chicago, 1126 East 59th

Street, Chicago, IL 60637, USA

K. A. Cagney

e-mail: kacagney@uchicago.edu likely than their White counterparts to attend a highquality dialysis facility (odds ratio (OR) 0.86) and those disparities persist, though are reduced, even after adjusting for region and neighborhood poverty and percent African-American. In predominately AfricanAmerican neighborhoods, individuals lived closer to high-quality facilities $(B=-5.92)$, but were $53 \%$ less likely to receive dialysis there (OR 0.47 , highest group versus lowest, $p<0.05)$. Living in a predominately African-American neighborhood explains $24 \%$ of racial disparity in attending a high-quality facility.

Conclusions African-Americans' proximity to high-quality facilities does not lead to receiving care there. Institutional and social barriers may also play an important role in where people receive dialysis.

Keywords Access $\cdot$ Hemodialysis $\cdot$ Quality of care $\cdot$ Racial disparity

C. Maene $\cdot$ T. Schuble

Social Science Computing Center, GIS Services, University of Chicago, 1155 E. 60th St., Chicago, IL 60637, USA

C. Maene

e-mail: cmaene@uchicago.edu

T. Schuble

e-mail: tschuble@uchicago.edu

K. A. Cagney

Population Research Center, NORC at the University of Chicago,

Chicago, IL, USA

K. A. Cagney

Department of Health Studies, University of Chicago, 1155 East 60th

St., Chicago, IL 60637, USA 


\section{Introduction}

African-Americans with end-stage renal disease (ESRD) face widespread disparities in access and quality of care compared to Whites [1-5]. To date, systemic differences in health-care access and outcomes have been less fully explored. Distance to a health-care facility is a potentially important determinant of individuals' access to care. For many patients with ESRD, distance from their dialysis facility may be particularly important due to the thrice-weekly hemodialysis treatment requirement. Two US studies have shown that most people in urban areas live within $30 \mathrm{~min}$ of their dialysis facility, and that longer travel time was associated with greater mortality and worse health-related quality of life [6, 7]. However, to our knowledge, no study has examined racial disparities in proximity to dialysis facilities.

In addition, systematic differences in care across neighborhoods or regions may also contribute to racial disparities in quality of care in dialysis facilities. Prior investigations suggest that dialysis facilities vary significantly regarding dialysis adequacy, anemia management, and renal transplant referral [4, 8-11]. Worse dialysis outcomes and reduced access to transplantation have also been associated with neighborhood factors such as poverty, urbanicity, and the proportion of African-Americans residing in the neighborhood [11-14]. Due to ongoing residential segregation, African-Americans and Whites tend to live in separate neighborhoods. These differences could translate to differential access to high-quality dialysis facilities. While prior work has demonstrated that African-Americans are less likely to dialyze in high-quality dialysis facilities, it is unknown whether this is due to racial differences in proximity to these facilities [11, 15].

Two competing pathways could explain AfricanAmericans' reduced access to high-quality dialysis facilities. First, African-Americans could live further from high-quality dialysis facilities which, in turn, reduces their likelihood of choosing to dialyze there. Another potential pathway is that African-Americans live closer to high-quality dialysis facilities than their White counterparts but still do not obtain care there. In this case, African-Americans could either be less likely to select those high-quality facilities for their care or to be accepted into those facilities. We sought to determine whether African-Americans and Whites differ in proximity to dialysis facilities, both overall and those of high quality. Additionally, we sought to determine whether African-Americans and Whites differed in access to high-quality facilities and if distance from the facility was associated with differential access.

\section{Methods}

Subjects and Data

First, we created the cohort using the United States Renal Data System (USRDS), a comprehensive dataset of patients with ESRD. We included all urban, non-Hispanic Whites and African-Americans aged 18-65 initiating in-center hemodialysis between January 2005 and December 31, 2008. We defined an urban area using both the Urbanized Areas (UA) and Urban Clusters (UC) of the 2010 US Census Urban Area Cartography Files [16]. We used a USRDS crosswalk file to link individuals to their dialysis facilities in the Centers for Medicare and Medicaid Services (CMS) ESRD Quality Incentive Program (QIP) file which provided information on facility address, dialysis facility characteristics, and facility quality outcomes for 2007. We applied the 2010 CMS definition for high-quality facility scoring to the 2007 data. We excluded individuals who could not be matched to a dialysis center $(n=2,154)$. Finally, we used the 2007-2011 American Community Survey by Zip Code Tabulation Areas (ZCTAs) to derive the neighborhood characteristics for each individual's home ZIP code at time of dialysis initiation. The final analytic file contains individuals nested within dialysis centers linked to a dialysis facility and residential neighborhood descriptors.

\section{Outcomes and Covariates}

\section{Outcomes}

Our outcomes were distance from patients' home to (1) their dialysis facility, (2) the nearest dialysis facility, and (3) the nearest high-quality dialysis facility. We also examined individuals' likelihood of dialyzing at a highquality facility. We defined the nearest facility as the facility that was the shortest straight-line distance from patient's home ZIP code. High-quality dialysis facilities were defined as those with a total performance score (TPS) greater than 26 (out of 30), based on the ESRD Quality Incentive Program scoring algorithm which gave a 1-10 rating for the proportion of patients with (1) a hemoglobin $(\mathrm{Hgb})<10 \mathrm{~g} / \mathrm{dL}$, (2) $\mathrm{Hgb}>12 \mathrm{~g} / \mathrm{dL}$, and (3) urea reduction rate $>65[17]$.

\section{Predictor and Covariates}

The main predictor is the racial difference between nonHispanic Whites (reference group $=0$ ) and AfricanAmericans (comparison group $=1$ ). In the USRDS, subjects' race and ethnicity was obtained from the Medical Evidence form using patient self-report. 
Individual covariates include gender and age at dialysis initiation (by quartile). Neighborhood-level characteristics include percent African-American and percent of population below the Federal Poverty Level which were right-skewed and divided into quartiles to create categorical variables. Region indicator variables-Northeast, Midwest, South, and West-were created from the 18 End-Stage Renal Disease Networks, regional entities responsible for organization, health planning, and quality improvement tasks for ESRD care.

\section{Analysis}

Five-digit residential ZIP code, the most detailed patient location available in USRDS, was used as a proxy for the patient's residence. Travel distance was the straight-line distance between the race-specific population weighted center of the patient's residential five-digit ZIP code and the corresponding dialysis center address $[18,19]$.

To calculate the race-specific population center of each ZIP code, we first calculated the sum of geometric centers of blocks within the ZIP code which was weighted by the race-specific population and then divided by the total group population in the ZIP code in order to produce the population-weighted mean geometric center. The geometric centroid (latitude and longitude) of all blocks in the US ZIP code as well as the 2010 population of each race group were obtained from the Missouri Census Data Center [20]. Then, dialysis facilities were assigned with geographic coordinates based on their reported addresses using ArcGIS Streetmap Premium (ESRI, Redlands, CA). Finally, straight-line travel distance between patient's residential ZIP code and the corresponding dialysis center was calculated in Stata using Vincenty (Haversine formula), a user-written program.

First, we examined the bivariate association between our outcomes of interest - patient distance to current, nearest, and nearest high-quality dialysis facility - and our covariates of interest stratified by race. Then we used linear regression to characterize the associations between our outcomes of interest and individual demographic characteristics. In addition, we used logistic regression to determine the association between dialysis in a high-quality facility and our covariates. Variables were determined a priori and were sequentially added to the model to adjust first for individual characteristics, then neighborhood demographics, and finally region. Interaction was assessed between neighborhood demographic variables (proportion African-American and proportion below poverty) for likelihood of attending a high-quality facility. We used the Breen scaling method to determine the effect of neighborhood on racial differences in likelihood of attending a high-quality facility $[21,22]$. Breen scaling is used here to calculate the change in the coefficient of the variable of the interest attributed to the inclusion of confounding variables when employing logit and probit models. Although patients were nested within neighborhoods and dialysis centers, we were unable to use multilevel modeling because not all higher level units (dialysis units or neighborhoods) had sufficient number $(n \geq 5)$ of observations [23]. To account for within-unit correlation, the sandwich estimate was used with ZIP code of residence as a cluster variable. We used chi-square to assess differences for categorical variables, and $t$-tests and ANOVA to assess differences for linear variables. For all analyses, a two-tailed significance level of $p<0.05$ was used. All analyses were conducted using Stata, version 12.0.

\section{Results}

Patient Characteristics

Our final sample included 183,190 patients, $49 \%$ White and $51 \%$ African-American (Table 1). On average, the AfricanAmerican patients were younger (49.6 versus 52.6\%) and less likely to be male (53.0 versus $57.8 \%$ ). In general, AfricanAmerican respondents were significantly more likely to live in high poverty (42.3 versus $10.7 \%$ ) and predominately AfricanAmerican neighborhoods (45.6 versus $4.0 \%$ ) than their White counterparts (all $p<0.05$ ).

The median distance from patients' home to their dialysis facility was 4.11 miles (mi). African-Americans lived $3.62 \mathrm{mi}$ from their dialysis facility, significantly closer than Whites $(4.70 \mathrm{mi})$. African-Americans were less likely to dialyze in high-quality facilities than Whites ( 52.1 v $55.9 \%, p<0.05)$. In unadjusted analysis, African-Americans lived closer to highquality facilities compared to Whites (2.26 versus $3.36 \mathrm{mi}$ ) (all $p<0.05$ ).

\section{Overview of Multivariable Results}

In the fully adjusted models (Table 2), AfricanAmericans lived a half-mile closer to the nearest dialysis facility $(B=-0.52)$ but on average traveled the same distance to their own dialysis facility than their White counterparts. In addition, individuals lived closer to a high-quality facility as the proportion of AfricanAmericans in the neighborhood increased $(B=-5.92$, highest versus lowest quartile). Further, initial analysis (Table 3, model 1) shows that African-Americans are $14 \%$ less likely than their White counterparts to attend a high-quality dialysis facility (odds ratio (OR) 0.86 ) and that disparity is even more striking after control- 
Table 1 Descriptive statistics, overall, and by race
${ }^{a}$ High-quality dialysis facilities are defined as those with a total performance score (TPS) greater than 26 (out of 30), based on the ESRD Quality Improvement Plan algorithm for scoring dialysis facilities which gave a $1-10$ rating for the proportion of patients with a hemoglobin $(\mathrm{Hgb})<10 \mathrm{~g} / \mathrm{dL}$, $\mathrm{Hgb}>12 \mathrm{~g} / \mathrm{dL}$, and urea reduction rate $\geq 65 \%$

${ }^{*} p<0.01$, African-American versus White

\begin{tabular}{|c|c|c|c|}
\hline Variable & $\begin{array}{l}\text { Overall, } \\
N=183,190\end{array}$ & $\begin{array}{l}\text { White, } N=90,606 \\
(49.46 \%)\end{array}$ & $\begin{array}{l}\text { African-American, } \\
N=92,584 \\
(50.54 \%)\end{array}$ \\
\hline \multicolumn{4}{|c|}{ Individual level characteristics } \\
\hline Age* (mean, $95 \% \mathrm{CI}$ ) & $\begin{array}{l}51.17(52.94 \\
53.06)\end{array}$ & $\begin{array}{l}52.64(54.93 \\
55.07)\end{array}$ & $\begin{array}{l}49.61(50.92 \\
51.08)\end{array}$ \\
\hline \multicolumn{4}{|l|}{ Age quartile* } \\
\hline Quartile 1 below 45 & $26.92 \%$ & $21.85 \%$ & $31.88 \%$ \\
\hline Quartile $245-53$ & $23.57 \%$ & $21.94 \%$ & $25.17 \%$ \\
\hline Quartile $353-60$ & $25.50 \%$ & $29.89 \%$ & $25.50 \%$ \\
\hline Quartile 4 over 60 & $21.84 \%$ & $26.32 \%$ & $17.45 \%$ \\
\hline Gender (male)* & $55.38 \%$ & $57.81 \%$ & $53.00 \%$ \\
\hline \multicolumn{4}{|c|}{ Neighborhood level characteristics } \\
\hline \multicolumn{4}{|c|}{ Percent African-American* (\%) } \\
\hline Quartile $1(0-5)$ & $24.98 \%$ & $45.93 \%$ & $4.47 \%$ \\
\hline Quartile $2(5-18)$ & $25.00 \%$ & $33.45 \%$ & $16.74 \%$ \\
\hline Quartile 3 (18-50) & $25.00 \%$ & $16.61 \%$ & $33.21 \%$ \\
\hline Quartile 4 (50-100) & $25.02 \%$ & $4.00 \%$ & $45.58 \%$ \\
\hline \multicolumn{4}{|l|}{ Percent poverty* (\%) } \\
\hline Quartile $1(0-9)$ & $22.40 \%$ & $32.84 \%$ & $12.19 \%$ \\
\hline Quartile $2(9-15)$ & $25.18 \%$ & $31.94 \%$ & $18.56 \%$ \\
\hline Quartile 3 (15-23) & $25.73 \%$ & $24.47 \%$ & $26.95 \%$ \\
\hline Quartile 4 (23-100) & $26.69 \%$ & $10.74 \%$ & $42.30 \%$ \\
\hline \multicolumn{4}{|l|}{ Region* } \\
\hline Midwest & $31.22 \%$ & $35.30 \%$ & $27.23 \%$ \\
\hline South & $47.08 \%$ & $36.89 \%$ & $57.04 \%$ \\
\hline Northeast & $15.63 \%$ & $17.96 \%$ & $13.35 \%$ \\
\hline West & $6.07 \%$ & $9.85 \%$ & $2.37 \%$ \\
\hline \multicolumn{4}{|l|}{ Outcome } \\
\hline \multicolumn{4}{|c|}{$\begin{array}{l}\text { Distance from patients' home to their } \\
\text { own dialysis facility* }\end{array}$} \\
\hline \multicolumn{4}{|c|}{$\begin{array}{l}\text { Distance from patients' home to the } \\
\text { nearest facility* }\end{array}$} \\
\hline Median $(95 \% \mathrm{CI})$ & $1.76(1.75,1.77)$ & $2.17(2.16,2.18)$ & $1.53(1.53,1.54)$ \\
\hline \multicolumn{4}{|c|}{$\begin{array}{l}\text { Distance from patients' home to the } \\
\text { nearest } \\
\text { high quality facility }{ }^{\mathrm{a}, *}\end{array}$} \\
\hline Median $(95 \% \mathrm{CI})$ & $2.70(2.69,2.72)$ & $3.36(3.33,3.39)$ & $2.26(2.25,2.28)$ \\
\hline \multicolumn{4}{|c|}{$\begin{array}{l}\text { Percent population who go to the highest } \\
\text { quality facility* }\end{array}$} \\
\hline & $54.00 \%$ & $55.95 \%$ & $52.10 \%$ \\
\hline
\end{tabular}

ling for distance to high-quality facility (model 2, OR $0.69)$. After controlling for individual and neighborhood characteristics and region, individuals in predominately African-American neighborhoods are $53 \%$ less likely to receive dialysis in a high-quality facility (OR 0.47 , both highest quartile versus lowest, $p<0.05$, Table 3, model 5). Living in a predominately AfricanAmerican neighborhood explains $24 \%$ of AfricanAmericans' reduced likelihood of attending a highquality facility (Table 3).
Multivariable Results: Distance to Nearest Dialysis Facility

Factors associated with living closer to the nearest dialysis facility (Table 2, full model 1) include African-American race ( $B=-0.52)$, male gender $(B=0.04)$, having an increasing proportion of African-Americans in the neighborhood ( $B=-2.33$, highest quartile versus lowest), and residence in the Northeast ( $B=-0.42$, compared to the Midwest) (all $p<0.001)$. Individuals in the South and West lived farther from the nearest center. 
Table 2 Multivariable regression for dialysis facility distance between patient ZIP code and the nearest, patients' own, and nearest high-quality dialysis facility

\begin{tabular}{|c|c|c|c|c|c|c|}
\hline \multirow[t]{3}{*}{ Variable } & \multirow{2}{*}{\multicolumn{2}{|c|}{$\begin{array}{l}\text { Distance in miles between patient } \\
\text { ZIP code and the nearest facility } \\
\text { Beta (standard error) }\end{array}$}} & \multirow{2}{*}{\multicolumn{2}{|c|}{$\begin{array}{l}\text { Distance in miles between patient } \\
\text { ZIP code and the facility address } \\
\text { Beta (standard error) }\end{array}$}} & \multirow{2}{*}{\multicolumn{2}{|c|}{$\begin{array}{l}\text { Distance in miles between patient } \\
\text { ZIP code to the high quality facility } \\
\text { Beta (standard error) }\end{array}$}} \\
\hline & & & & & & \\
\hline & Base model 1 & Full model 1 & Base model 2 & Full model 2 & Base model 2 & Full model 3 \\
\hline \multicolumn{7}{|c|}{ Individual level characteristics } \\
\hline Race (AA) & $-1.44(0.02)^{* * *}$ & $-0.52(0.22)^{* * *}$ & $-2.16(0.16)^{* * *}$ & $0.27(0.21)$ & $-2.66(0.04)^{* * *}$ & $-0.93(0.05)^{* * *}$ \\
\hline Gender (male) $)^{* *}$ & $-0.03(0.02)$ & $-0.0(0.02)$ & $0.15(0.16)$ & $0.15(0.16)$ & $-0.11(0.04)^{* *}$ & $-0.08(0.03)$ \\
\hline \multicolumn{7}{|l|}{ Age in quartile** } \\
\hline Quartile 1 below 45 & Referent & Referent & Referent & Referent & Referent & Referent \\
\hline Quartile $245-53$ & $-0.06(0.02)^{*}$ & $-0.03(0.02)$ & $-2.06(0.22)^{* * *}$ & $-1.91(0.22)^{* * *}$ & $-0.14(0.06)^{*}$ & $-0.06(0.06)$ \\
\hline Quartile $353-60$ & $-0.04(0.02)$ & $-0.01(0.02)$ & $-2.71(0.22)^{* * *}$ & $-2.55(0.22)^{* * *}$ & $-0.05(0.06)$ & $0.04(0.05)$ \\
\hline Quartile 4 over 60 & $-0.04(0.03)$ & $-0.01(0.02)$ & $-2.91(0.23)^{* * *}$ & $-2.72(0.23)^{* * *}$ & $-0.06(0.06)$ & $0.06(0.06)$ \\
\hline \multicolumn{7}{|c|}{$\begin{array}{l}\text { Neighborhood level characteristics } \\
\text { and region } \\
\text { Percent African-American** (\%) }\end{array}$} \\
\hline Quartile $1(0-5)$ & & Referent & & Referent & & Referent \\
\hline Quartile 2 (5-18) & & $-1.57(0.03)^{* * *}$ & & $-2.51(0.24)^{* * *}$ & & $-2.91(0.06)^{* * *}$ \\
\hline Quartile 3 (18-50) & & $-1.88(0.03)^{* * *}$ & & $-3.76(0.28)^{* * *}$ & & $-4.02(0.07)^{* * *}$ \\
\hline Quartile 4 (50-100) & & $-2.33(0.03)^{* * *}$ & & $-5.64(0.32)^{* * *}$ & & $-5.92(0.08)^{* * *}$ \\
\hline \multicolumn{7}{|l|}{ Percent poverty** (\%) } \\
\hline Quartile 1 (0-9) & & Referent & & Referent & & Referent \\
\hline Quartile 2 (9-15) & & $-0.01(0.02)$ & & $0.27(0.23)$ & & $1.54(0.05)^{* * *}$ \\
\hline Quartile 3 (15-23) & & $0.02(0.03)$ & & $0.15(0.24)$ & & $2.61(0.07)^{* * *}$ \\
\hline Quartile 4 (23-100) & & $-0.05(0.03)$ & & $-0.89(0.27)^{* * *}$ & & $2.24(0.08)^{* * *}$ \\
\hline \multicolumn{7}{|l|}{ Region** } \\
\hline Midwest & & Referent & & Referent & & Referent \\
\hline South & & $0.54(0.02)^{* * *}$ & & $2.90(0.19)^{* * *}$ & & $1.76(0.05)^{* * *}$ \\
\hline Northeast & & $-0.51(0.03)^{* * *}$ & & $-2.42(0.25)^{* * *}$ & & $-0.89(0.06)^{* * *}$ \\
\hline West & & $0.26(0.04)^{* * *}$ & & $3.27(0.36)^{* * *}$ & & $-1.05(0.09)^{* * *}$ \\
\hline
\end{tabular}

High-quality dialysis facilities are defined as those with a total performance score (TPS) $>26$ (out of 30), based on the ESRD Quality Improvement Plan algorithm for scoring dialysis facilities which gave a 1-10 rating for the proportion of patients with a hemoglobin $(\mathrm{Hgb})<10 \mathrm{~g} / \mathrm{dL}, \mathrm{Hgb}>12 \mathrm{~g} / \mathrm{dL}$, and urea reduction rate $\geq 65 \%$. Base model examines association between patient distance to dialysis facilities and individual characteristics including race, gender, and age. The full model adjusts for neighborhood characteristics (i.e., percent AA and poverty) and region to explore the underlying mechanism or process by which race influences distances through neighborhood-level mediators

$* p<0.05 ; * * p<0.01 ; * * * p<0.001$

\section{Multivariable Results: Distance to Patient Dialysis Facility}

In the final adjusted analysis (Table 2, full model 2), factors associated with living closer to patients' current dialysis facility include older age $(B=-2.72$, over 60 versus less than 45), larger proportion of AfricanAmericans in the neighborhood $(B=-5.64$, Q4 greater than $49 \%$ versus Q1, less than $3 \%$ ), higher neighborhood poverty $(B=-0.89$, Q4 greater than $23 \%$ versus Q1, less than $7 \%$ ), and residence in the Northeast ( $B=-2.42$, compared to the Midwest) (all $p<0.05)$. Individuals in the South and West lived farther from their center.
Multivariable Results: Distance to High-Quality Dialysis Facility

Factors associated with living closer to a high-quality dialysis facility (Table 2, full model 3) include AfricanAmerican race $(B=-0.93)$, larger proportion of AfricanAmericans in the neighborhood $(B=-5.92$, highest quartile versus lowest), and residence in the Northeast ( $B=$ -0.89 , compared to the Midwest) (all $p<0.001)$. Whites, those in high-poverty neighborhoods and those in the South and West lived farther from a high-quality facility. 
Table 3 Multivariable analysis for odds of attending high-quality dialysis facility with stepwise adjustment

\begin{tabular}{|c|c|c|c|c|c|}
\hline Variable & $\begin{array}{l}\text { Model 1: percent } \\
\text { characteristics } \\
\text { OR (95\% CI) }\end{array}$ & $\begin{array}{l}\text { Model 2: } 1+ \\
\text { distance to } \\
\text { high-quality } \\
\text { facility } \\
\text { OR }(95 \% \mathrm{CI})\end{array}$ & $\begin{array}{l}\text { Model 3: } 2+ \\
\text { region } \\
\text { OR }(95 \% \mathrm{CI})\end{array}$ & 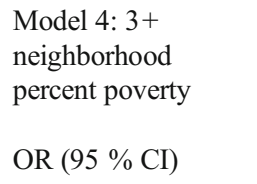 & $\begin{array}{l}\text { Model 5: 4+ } \\
\text { Neighborhood } \\
\text { percent African- } \\
\text { American } \\
\text { OR }(95 \% \mathrm{CI})\end{array}$ \\
\hline \multicolumn{6}{|l|}{ Individual level characteristics } \\
\hline Race (AA) & $0.86(0.81,0.90)^{* * *}$ & $0.69(0.66,0.72)^{* * *}$ & $0.70(0.67,0.73)^{* * *}$ & $0.71(0.68,0.74)^{* * *}$ & $0.88(0.85,0.91)^{* * *}$ \\
\hline Gender (male)* & $0.97(0.96,0.99)^{* *}$ & $0.96(0.94,0.98)^{* * *}$ & $0.96(0.95,0.98)^{* * *}$ & $0.96(0.95,0.98)^{* * *}$ & $0.96(0.94,0.98)^{* * *}$ \\
\hline \multicolumn{6}{|l|}{ Age in quartile* } \\
\hline Quartile 1 below 45 & Referent & Referent & Referent & Referent & Referent \\
\hline Quartile $245-53$ & $1.00(0.97,1.02)$ & $0.99(0.96,1.02)$ & $0.99(0.96,1.01)$ & $0.99(0.96,1.01)$ & $0.99(0.96,1.02)$ \\
\hline Quartile $353-60$ & $1.00(0.97,1.02)$ & $0.99(0.97,1.02)$ & $1.00(0.97,1.02)$ & $1.00(0.97,1.02)$ & $1.00(0.97,1.03)$ \\
\hline Quartile 4 over 60 & $1.00(0.98,1.19)$ & $1.00(0.97,1.03)$ & $1.00(0.98,1.03)$ & $1.00(0.98,1.03)$ & $1.01(0.98,1.04)$ \\
\hline $\begin{array}{l}\text { Distance to the nearest } \\
\text { high-quality facility }\end{array}$ & & $0.92(0.91,0.92)^{* * *}$ & $0.92(0.91,0.92)^{* * *}$ & $0.92(0.91,0.92)^{* * *}$ & $0.91(0.90,0.91)^{* * *}$ \\
\hline \multicolumn{6}{|l|}{$\begin{array}{l}\text { Neighborhood level characteristics } \\
\text { and region } \\
\text { Region* }\end{array}$} \\
\hline Midwest & & & Referent & Referent & Referent \\
\hline South & & & $0.83(0.77,0.89)^{* * *}$ & $0.83(0.77,0.89)^{* * *}$ & $0.89(0.82,0.96)^{* * *}$ \\
\hline Northeast & & & $0.73(0.67,0.80)^{* * *}$ & $0.73(0.67,0.80)^{* * *}$ & $0.72(0.66,0.79)^{* * *}$ \\
\hline West & & & $0.86(0.76,0.97)^{*}$ & $0.85(0.76,0.96)^{* *}$ & $0.74(0.66,0.83)^{* * *}$ \\
\hline \multicolumn{6}{|l|}{ Percent poverty* $(\%)$} \\
\hline Quartile $1(0-9)$ & & & & Referent & Referent \\
\hline Quartile $2(9-15)$ & & & & $1.04(0.96,1.12)$ & $1.11(1.03,1.20)^{* *}$ \\
\hline Quartile 3 (15-23) & & & & $1.06(0.97,1.16)$ & $1.21(1.10,1.32)$ \\
\hline Quartile $4(23-100)$ & & & & $0.96(0.87,1.05)$ & $1.22(1.10,1.36)$ \\
\hline \multicolumn{6}{|l|}{ Percent African-American* } \\
\hline Quartile $1(0-5)$ & & & & & Referent \\
\hline Quartile $2(5-18)$ & & & & & $0.69(0.64,0.75)^{* *}$ \\
\hline Quartile 3 (18-50) & & & & & $0.62(0.56,0.68)^{* *}$ \\
\hline Quartile 4 (50-100) & & & & & $0.47(0.42,0.53)^{* * *}$ \\
\hline $\begin{array}{l}\text { Percent change in the coefficients } \\
\text { (for race) attributable to } \\
\text { additive variables }{ }^{\mathrm{a}}\end{array}$ & $19.77 \%$ & $1.45 \%$ & $1.43 \%$ & $23.94 \%$ & \\
\hline
\end{tabular}

High-quality dialysis facilities are defined as those with a total performance score (TPS) $>26$ (out of 30), based on the ESRD Quality Improvement Plan algorithm for scoring dialysis facilities which gave a 1-10 rating for the proportion of patients with a hemoglobin $(\mathrm{Hgb})<10 \mathrm{~g} / \mathrm{dL}, \mathrm{Hgb}>12 \mathrm{~g} / \mathrm{dL}$, and urea reduction rate $\geq 65 \%$. Models $1-5$ employ stepwise adjustment of (1) individual, (2) distance, (3) region, (4) neighborhood poverty, and (5) neighborhood percent African-American, respectively.

${ }^{a}$ Breen scaling method is used here to calculate the change in the coefficient of the variable of the interest attributed to the inclusion of confounding variables when employing logit and probit models. Percent change in the coefficients for African-American race attributable additive variables $=\left(\left(\beta_{y x}\right.\right.$ $\left.\left.-\beta_{y x z}\right) / \beta_{y x}\right) \times 100 \%$, where $\beta_{y x}$ is the odds ratio of $x$ (AA) for outcome $y$, and $\beta_{y x z}$ is the odds ratio of $x$ on $y$ adjusted for control variables $(z)$

${ }^{*} p<0.05 ; * * p<0.01 ; * * * p<0.001$

\section{Multivariable Results: Dialysis at a High-Quality Facility}

Table 3 demonstrates the odds of attending a high-quality dialysis facility with step-wise addition of variables. Examining individual characteristics (model 1) reveals that AfricanAmericans and males were significantly less likely to attend a high-quality facility (OR 0.86 and 0.97 , respectively, all $p<0.05$ ). After controlling for distance to the nearest high- quality facility (model 2), African-Americans were $31 \%$ less likely than their White counterparts to attend a high-quality facility (OR 0.69, $95 \%$ confidence interval (CI) 0.66, 0.72). African-American race remained significantly associated with lower likelihood of attending a high-quality dialysis facility even after controlling for region, neighborhood percent poverty, and neighborhood percent African-American (models 3, 4, and 5 respectively). In the fully adjusted model (model 5), 
African-Americans were still $12 \%$ less likely to attend a highquality facility than their White counterparts (OR 0.88, $95 \% \mathrm{CI}$ $0.85,0.91)$. Neighborhood racial composition accounted for $23.9 \%$ of the racial disparity in attending a high-quality facility.

In the fully adjusted model (Table 3 , model 5), living in the Midwest, in a moderate- to high-poverty neighborhood and having a lower proportion of African-Americans in the neighborhood were associated with an increased likelihood of attending a high-quality facility. Having a larger proportion of African-Americans in the neighborhood (OR 0.47, highest quartile versus lowest, $95 \%$ CI $0.42,0.53$ ) was associated with decreased likelihood of dialysis in a high-quality facility, even after controlling for neighborhood poverty. Surprisingly, individuals who lived closest to a high-quality facility were $8-9 \%$ less likely to attend a high-quality facility across all models.

\section{Discussion}

We found African-Americans' proximity to dialysis facilities did not translate into access.

Further, African-Americans appear to bypass closer facilities to travel to their own dialysis facility. In addition, although African-Americans lived a significantly shorter distance to high-quality dialysis facilities, they were not more likely to dialyze these facilities than their White counterparts. Our work showed that this difference was explained both by where they lived (region and neighborhood) and by than who they are (race). Living in a predominately African-American neighborhood was associated with a reduced likelihood of receiving dialysis in a high-quality facility despite living significantly closer to these facilities.

In addition, we found that after accounting for differences in region and neighborhood, the effect of race was attenuated. Region and neighborhood racial composition accounted for approximately $25 \%$ of differences by race. Our results are supported by prior work that contends that racial residential segregation plays an important role in continued health disparities for African-Americans [24-26]. African-Americans and Whites have had different migration patterns. AfricanAmericans are clustered in urban areas in the Northeast and Midwest and in both urban and rural areas in the South. In addition, even within the same areas, due to ongoing racial residential segregation African-Americans and Whites often live in separate communities. This continued separation by race leads to differences in access to the information, opportunities, and organizations which can impact health [24-26].

Our work underscores that access to health care is related to both physical distance and, potentially, "social distance." Nearby dialysis facilities may still be inaccessible for a variety of social reasons. Despite their proximity, nearby facilities may be "off their mental map" if they lie outside patient's activity space, the space within which people move about or travel in the course of their daily activities [27, 28]. Alternatively, patients may reject nearby facilities because they do not feel comfortable in the dialysis facility neighborhood or the facility itself.

In addition, African-Americans may be guided toward lower-quality dialysis facilities. Patients may also rely on their social networks and word of mouth from friends and family. Due to residential and social segregation, African-Americans' social networks are more likely to be closed and limited to those of their own race and neighborhood, which may limit information about facility quality [27, 29]. While facility quality ratings are publicly available online through Dialysis Facility Compare, patients need to know these ratings exist and have computer access for this online data [30]. AfricanAmericans may also be guided toward lower-quality facilities by health-care providers. For many patients, dialysis occurs emergently within a hospital setting which may require patients to rely on hospital-based providers for recommendations [31, 32]. These providers may steer patients toward particular facilities based on their referral practices, knowledge, or assumptions about patients' needs.

Even with appropriate knowledge and referral, AfricanAmericans may be less likely to be accepted at higherquality facilities. Unlike other medical services, patients are accepted in a dialysis facility rather than just deciding to receive care there. Due to greater patient demand, higherquality dialysis facilities may have a longer waiting list or more stringent selection criteria. Higher-quality dialysis facilities may also seek to maintain their quality outcomes by "cherry-picking," reducing access for patients perceived to be medically or socially complex, less well-insured or more likely to be nonadherent [33]. Our study is designed to determine association rather than causality. Our results, while important, raise additional questions. Further qualitative and quantitative work is needed to determine how individuals end up in their dialysis facilities and how we can equalize access to high quality facilities.

Access to high-quality dialysis facilities has important clinical significance. Poor performance in achieving targeted hemoglobin and greater dialysis adequacy, the dialysis facility outcomes measured by the Centers for Medicare and Medicaid Services (CMS) ESRD Quality Incentive Program (QIP), is associated with increased morbidity, mortality, and increased risk for hospitalization [34-37]. Patients whose care met quality indicators, including dialysis adequacy and achieving targeted hemoglobin, show a greater self-reported quality of life than those who do not [35].

We note several limitations to this study. First, we only had ZIP codes for patient residence so our neighborhood-level data was based on the ZIP code tabulation area. Second, we used straight-line distance to dialysis facility rather than driving distance or travel time. While some work has 
demonstrated that straight-line distance underestimates travel distance by $20-25 \%$ compared to road network, others have shown that over large geographical areas straight-line distance is highly correlated with travel time. Systematic underestimation may be inherent in the methods used; however, our method is unlikely to generate any bias in statistical models so long as the errors are not biased against any subpopulation $[38,39]$. Third, our measure of facility quality is based on the CMS QIP which may only partly reflect overall facility quality; however, this currently is the only comprehensive quality metric for dialysis facilities and is linked to reimbursement. Fourth, we focused our analysis to urban, African-Americans, and Whites under 65. We chose African-Americans and Whites due to their larger sample size and lower rates of misclassification in the USRDS. We selected patients under 65 because older patients may have varied residential mobility, making our initial home address and our distance measure less accurate. Older adults may have increased residential mobility as they move due medical illness, e.g., living with family or in a nursing home due to frailty or due to increased time for leisure and family, e.g., move to retirement communities or warmer areas [40]. Our choices increase our internal validity, but decrease our generalizability. Further work should examine the important issues of access to highquality dialysis care for rural and older patients with ESRD.

Overall, individuals in urban areas in the USA live close to a dialysis facility and close to a high-quality facility. We found that patients live, on average, $4 \mathrm{mi}$ from their chosen dialysis facility and less than $2 \mathrm{mi}$ to the nearest dialysis facility. Our work was consistent with previous studies that showed urban patients on hemodialysis do not travel far to their dialysis centers $[6,7,41]$. Having dialysis facilities close to where patients need them is a significant accomplishment, yet to be attained in rural areas in the USA and in many other countries. However, proximity does not equal access. Although AfricanAmericans live a shorter distance to high-quality dialysis facilities than their White counterparts, they are still less likely to receive dialysis in these facilities. This effect is explained both by location (neighborhood and region) and by race. The challenge continues to fully integrate African-Americans into both the communities and the opportunity structures in the USA. In the meantime, to improve the quality of care received by African-Americans with ESRD, further work should focus not only how to improve the dialysis facilities that primarily serve minorities but also to improve access to nearby highquality dialysis facilities.

Acknowledgments Dr. Saunders was supported by the Clinical Translational Science Award Clinical Scholar Program (KL2 RR0250000) from the National Center for Research Resources. Dr. Saunders had full access to all of the study data and takes responsibility for the integrity of the data and accuracy of the data analysis. An abstract of this paper was presented at the National Kidney Foundation Annual Meeting in Orlando, FL in April 2013.
Conflict of Interest The authors (Dr. Saunders, Ms. Lee, Ms. Maene, Mr. Schuble, Dr. Cagney) declare that they have no conflict of interest.

Ethical Standards No animal or human studies were carried out by the authors for this article. This study was deemed exempt by the University of Chicago Institutional Review Board.

\section{References}

1. Wolfe RA, Ashby VB, Milford EL, et al. Differences in access to cadaveric renal transplantation in the United States. Am J Kidney Dis. 2000;36(5):1025-33.

2. Ashby VB, Kalbfleisch JD, Wolfe RA, Lin MJ, Port FK, Leichtman AB. Geographic variability in access to primary kidney transplantation in the United States, 1996-2005. Am J Transplant. 2007;7(5 Pt 2):1412-23.

3. Navaneethan SD, Singh S. A systematic review of barriers in access to renal transplantation among African Americans in the United States. Clin Transplant. 2006;20(6):769-75.

4. Frankenfield DL, Rocco MV, Frederick PR, Pugh J, McClellan WM, Owen Jr WF. Racial/ethnic analysis of selected intermediate outcomes for hemodialysis patients: results from the 1997 ESRD Core Indicators Project. Am J Kidney Dis. 1999;34(4):721-30.

5. Reddan DN, Szczech LA, Klassen PS, Owen WF. Racial inequity in America's ESRD Program. Semin Dial. 2000;13(6):399-403.

6. Moist LM, Bragg-Gresham JL, Pisoni RL, et al. Travel time to dialysis as a predictor of health-related quality of life, adherence, and mortality: the Dialysis Outcomes and Practice Patterns Study (DOPPS). Am J Kidney Dis. 2008;51(4):641-50.

7. Stephens JM, Brotherton S, Dunning SC, et al. Geographic disparities in patient travel for dialysis in the United States. J Rural Health. 2013.

8. Alexander GC, Sehgal AR. Variation in access to kidney transplantation across dialysis facilities: using process of care measures for quality improvement. Am J Kidney Dis. 2002;40(4):824-31.

9. Fink JC, Armistead N, Turner M, Gardner J, Light P. Hemodialysis adequacy in Network 5: disparity between states and the role of center effects. Am J Kidney Dis. 1999;33(1):97-104.

10. Sehgal AR. Impact of quality improvement efforts on race and sex disparities in hemodialysis. JAMA. 2003;289(8):996-1000.

11. Saunders MR, Chin MH. Variation in dialysis quality measures by facility, neighborhood, and region. Med Care. 2013;51(5):413-7.

12. O'Hare AM, Johansen KL, Rodriguez RA. Dialysis and kidney transplantation among patients living in rural areas of the United States. Kidney Int. 2006;69(2):343-9.

13. Rodriguez RA, Sen S, Mehta K, Moody-Ayers S, Bacchetti P, O'Hare AM. Geography matters: relationships among urban residential segregation, dialysis facilities, and patient outcomes. Ann Intern Med. 2007;146(7):493.

14. Saunders MR, Cagney KA, Ross LF, Alexander GC. Neighborhood poverty, racial composition and renal transplant waitlist. Am J Transplant. 2010;10(8):1912-7.

15. Rodriguez RA, Sen S, Mehta K, Moody-Ayers S, Bacchetti P, O'Hare AM. Geography matters: relationships among urban residental segregation, dialysis facilities, and patient outcomes. Ann Intern Med. 2007.

16. Census Bureau. Urbanized areas cartographic boundary files. Department of Commerce, Geography Division; 2010.

17. Medicare program; end-stage renal disease quality incentive program. Final rule. Fed Regist;76(3):627-46.

18. VINCENTY: Stata module to calculate distances on the Earth's surface program. Boston College Department of Economics; 2003. 
19. Berke EM, Shi X. Computing travel time when the exact address is unknown: a comparison of point and polygon ZIP code approximation methods. Int J Health Geogr. 2009:8(23).

20. Missouri Census Data Center, Office of Social and Economic Data Analysis (OSEDA). Tools and Resources Related to U.S. ZIP Codes. http://mcdc.missouri.edu/webrepts/geography/ZIP.resources.html. Accessed May 20, 2014

21. Breen R, Karlson KB, Holm A. Total, direct, and indirect effects in logit and probit models. Sociol Methods Res. 2013;42(2):164-91.

22. Karlson KB, Holm A, Breen R. Comparing regression coefficients between same-sample nested models using logit and probit. A new method. Sociol Methodol. 2012;42(1):286-313.

23. Mass CJM, Hox JJ. Sufficient sample sizes for multi-level modeling. Methodol Eur J Res Methods Behav Soc Sci. 2005;1(3):86-92.

24. Diez Roux AV, Mair C. Neighborhoods and health. Ann N Y Acad Sci. 2010;1186(1):125-45.

25. Williams DR, Collins C. Racial residential segregation: a fundamental cause of racial disparities in health. Public Health Rep. 2001;116(5):404.

26. Hasnain-Wynia R, Baker DW, Nerenz D, et al. Disparities in health care are driven by where minority patients seek care: examination of the hospital quality alliance measures. Arch Intern Med. 2007;167(12):1233-9.

27. Krivo LJ, Washington HM, Peterson RD, Browning CR, Calder CA, Kwan M-P. Social isolation of disadvantage and advantage: the reproduction of inequality in urban space. Soc Forces.

28. Vallee J, Cadot E, Grillo F, Parizot I, Chauvin P. The combined effects of activity space and neighbourhood of residence on participation in preventive health-care activities: the case of cervical screening in the Paris metropolitan area (France). Health Place. 2010;16(5): $838-52$.

29. Rankin BH, Quane JM. Neighborhood poverty and the social isolation of inner-city African American families. Soc Forces. 2000;79(1): 139-64.
30. Dialysis Facility Compare. In: Medicare.gov. Centers for Medicare \& Medicaid Services. Accessed May 16, 2013.

31. Crews DC, Jaar BG, Plantinga LC, Kassem HS, Fink NE, Powe NR. Inpatient hemodialysis initiation: reasons, risk factors and outcomes. Nephron Clin Pract. 2009;114(1):c19-28.

32. Chiu K, Alam A, Iqbal S. Predictors of suboptimal and crash initiation of dialysis at two tertiary care centers. Hemodial Int. 2012;16: S39-46.

33. Desai AA, Bolus R, Nissenson A, et al. Is there "cherry picking" in the ESRD Program? Perceptions from a Dialysis Provider Survey. Clin J Am Soc Nephrol. 2009;4(4):772-7.

34. Lacson Jr E, Wang W, Hakim RM, Teng M, Lazarus JM. Associates of mortality and hospitalization in hemodialysis: potentially actionable laboratory variables and vascular access. Am J Kidney Dis. 2009;53(1):79-90.

35. Lacson Jr E, Xu J, Lin SF, Dean SG, Lazarus JM, Hakim R. Association between achievement of hemodialysis quality-of-care indicators and quality-of-life scores. Am J Kidney Dis. 2009;54(6): 1098-107.

36. Lacson Jr E, Wang W, Lazarus JM, Hakim RM. Hemodialysis facility-based quality-of-care indicators and facility-specific patient outcomes. Am J Kidney Dis. 2009;54(3):490-7.

37. Van Wyck D, Robertson J, Nissenson A, Provenzano R, Kogod D. Relationship among length of facility ownership, clinical performance, and mortality. Clin J Am Soc Nephrol. 2010;5(2):248-51.

38. Bliss RL, Katz JN, Wright EA, Losina E. Estimating proximity to care: are straight line and zipcode centroid distances acceptable proxy measures? Med Care. 2012;50(1):99-106.

39. Phibbs CS, Luft HS. Correlation of travel time on roads versus straight line distance. Med Care Res Rev. 1995;52(4):532-42.

40. Sergeant JF, Ekerdt DJ, Chapin R. Measurement of late-life residential relocation: why are rates for such a manifest event so varied? J Gerontol Ser B Psychol Sci Soc Sci. 2008;63(2):S92-8.

41. Prakash S, Coffin R, Schold J, et al. Travel distance and home dialysis rates in the United States. Perit Dial Int. 2014;34(1):24-32. 